\title{
Phases quantification in DP600 steel welded by GTAW process using SEM and atomic force microscopy ${ }^{1}$
}

\author{
G.Y. Pérez Medina ${ }^{a}$, E. Hurtado Delgado ${ }^{a}$, A. F. Miranda Pérez $z^{a}$, H. Lopez Ferreira ${ }^{b}$ \\ a Postgraduate Studies, Corporación Mexicana de Investigación en Materiales, Saltillo, \\ Coahuila, México \\ ${ }^{b}$ Materials Department, University of Wisconsin-Milwaukee, Milwaukee WI 53201, USA
}

Received: February 28, 2016; Revised: October 18, 2016; Accepted: January 25, 2017

\begin{abstract}
The automotive industry is constantly under several challenges in many aspects, such as development of new materials and improvement their manufacturability. In order to achieve light weight, reduced emissions and ensure conductor safety, advanced high strength steels (AHSS) are able to fulfill these requirements. Dual phase steels (DP) are well suited for light weighing car body constructions. The gas tungsten arc welding (GTAW) process is focused in literature as an alternative choice for joining AHSS steels; this study is held to disclose the exhibited microstructural constituents. In addition, quantitative determinations of the volume $\%$ of phases in the various weld regions were made. The relative amounts of lower bainite (LB), upper bainite (UB), and polygonal ferrite (PF) in the heat affected zone (HAZ) were determined by image analysis from optical microscopy $(\mathrm{OM})$ and scanning electron microscopy (SEM). It was found that GTAW promoted the development of significant amounts of LB in the HAZ $(50.89 \%)$. In contrast atomic force microscopy (AFM) leads to quantify the different phases by the morphology, height and roughness, it was found that martensite (M) dropped down to $7.5 \%$ in the intercritical zone (IZ) although PF increases to $92.5 \%$ compared with the base metal (BM).
\end{abstract}

Keywords: $A F M$, SEM, AHSS, GTAW, DP steels

\section{Introduction}

In an attempt to reduce automobile vehicle weight and enhance passenger safety, multiphase AHSS steels such as DP steel has been developed. In recent years these steels have been subject of extensive interest because of their unique combination of mechanical properties, high strength associate with good formability ${ }^{1-3}$. Their microstructure consists of martensite and ferrite ${ }^{4-6}$. Therefore, it is only comprehensible to utilize high resistant materials in order to reduce the cross sectional area (thickness), hence to diminish the structural weight.

Certain components require materials that are thinner and lighter, and can more difficult to join. In an ideal world "the best joining method is no joining at all". This quote captures a designer's frustration with the need to include joints which then create potential areas of weakness in the automotive body $^{7}$, the GTAW process is an economy welding method; however, very limited studies about the GTAW joint have been reported for the DP steels, ${ }^{8}$. The welding processes, due to their thermal cycle, might inflict alterations on base metal phases $^{9-11}$, heating of these materials leads to the tempering of martensite in the intercritical zone producing a softening zone, in contrast in the HAZ the DP steel can be made to undergo diffusionless transformation due to a cooling rate is fast enough to prevent transformation by an alternative mechanism involving the diffusional movement of atoms

\footnotetext{
${ }^{1}$ Article presented and selected from "The XXIV International Materials Research Congress (IMRC) 2015". Symposium 5B "Structural and Chemical Characterization of Metals, Alloys and Compounds". Cancun, Mexico August 16-20, 2015.

* e-mail: gladysperez@comimsa.com
}

conducting to high hardness zones ${ }^{12}$. Various characterization techniques have been employed for determinations of phases in these steels including X-ray diffraction and color metallography ${ }^{5,13}$. Nevertheless, there is limited work on the characterization and quantification of the phases developed in the different regions of DP steels joined by GTAW process.

Accordingly, in this work divers analytical techniques for microstructure development were considered and compared with AFM estimations of the various phases developed in a DP steel joined by using GTAW process. In recent years atomic force microscopy has demonstrated versatility in the characterization of surface morphology and interaction forces ${ }^{14,15}$. It is a high resolution imaging technique, using a sharp probe as a stylus to examine the surface in three dimensions to sub-nanometer resolution and it is a versatile tool for the study and characterization of DP steels. Through production of high resolution imaging it leads to quantify the different phases by the morphology, height and roughness. In particular, the exhibited volume percentages of $\mathrm{M}$ and $\mathrm{PF}$ in the various welded regions of the BM and IZ were quantified in order to disclose possible phase transformation reactions.

\section{Experimental}

\subsection{Microstructural and microhardness characterization}

The investigated DP 600 steel was supplied in the form of $2.5 \mathrm{~mm}$ thick sheet. Table 1 gives the chemical 
composition of the DP600 steel. In addition, microstructural characterization and phase quantification were carried out by Olympus OM, Jeol SEM and AFM using an Image-Pro Plus analyzer. After welding, the specimens were encapsulated in a hot compression thermo-setting resin and wet ground with silicon carbide abrasive paper up to 2000 grit, then polished with cloths loaded with a polycrystalline diamond paste of 3.0 and $1.0 \mu \mathrm{m}$ grit, down to $0.05 \mu \mathrm{m}$ alumina. After polishing, the sample surface was chemically etched with $2 \%$ nital about 7 seconds for OM and SEM. In the case of AFM the sample surface was chemically etched by $0.5 \%$ nital around 20 seconds. A Jeol JSPM5200 AFM was used with scan heads of nominally $50 \times 50 \mu \mathrm{m}^{2}$ scanning area and a maximum $\mathrm{Z}$ range of $14 \mu \mathrm{m}$. The AFM was used in the tapping mode to obtain topography and phase contrast scans. With this mode of operation the cantilever is allowed to oscillate at a sufficient level of frequency which allows it to make contact and disengage repeatedly with the sample surface $^{16}$. Imaging frequencies are typically on the order of several tens of $\mathrm{kHz}$. The exhibited hardness of the various welding regions was determined by Vickers microhardness profile, using microhardness Tukon 2500, Wilson Hardness.

\subsection{GTAW Process}

The welding conditions using a butt joint with a gap of $1.6 \mathrm{~mm}$ in the GTAW autogenous process were a heat input of $3.4(\mathrm{KJ} / \mathrm{mm})$, using 60 amperes, 18 volts and welding speed $19 \mathrm{~mm} / \mathrm{min}$. A $99.99 \%$ Ar was used as a shielding gas and a tungsten electrode EWTh-2. The welding equipment employed was a Miller syncrowave 250 .

\section{Results and Discussion}

\subsection{Welded microstructure}

Metallography determination closely followed the published methods for identification and characterization of phases in DP steels ${ }^{5,16}$. The exhibited microstructural features of the DP steels in as received condition are shown in Figure 1. Notice the presence of PF that can be clearly distinguished from $M$ produced by annealing the steel at an inter-critical temperature ( $\alpha+\gamma$ region) and the rapidly cooling to room temperature with a fine-grained structure with acicular lath. An overall view of the cross section welding is showing in Figure $2 \mathrm{a}$. The resultant microstructures found in the IZ, HAZ 2, HAZ 1 and FZ using SEM are shown in Figures $2 \mathrm{~b}, 2 \mathrm{c}, 2 \mathrm{~d}$ and $2 \mathrm{e}$, respectively.

The different microstructures developed in the IZ shows that apparently, this region underwent to transformation occurring

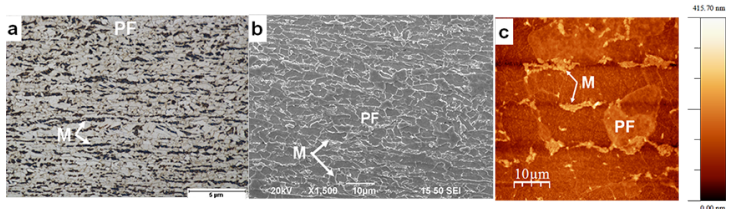

Figure 1. Micrographs of the AHSS DP600 in the BM: a) OM, b) SEM and c) AFM. Etchant: Nital.
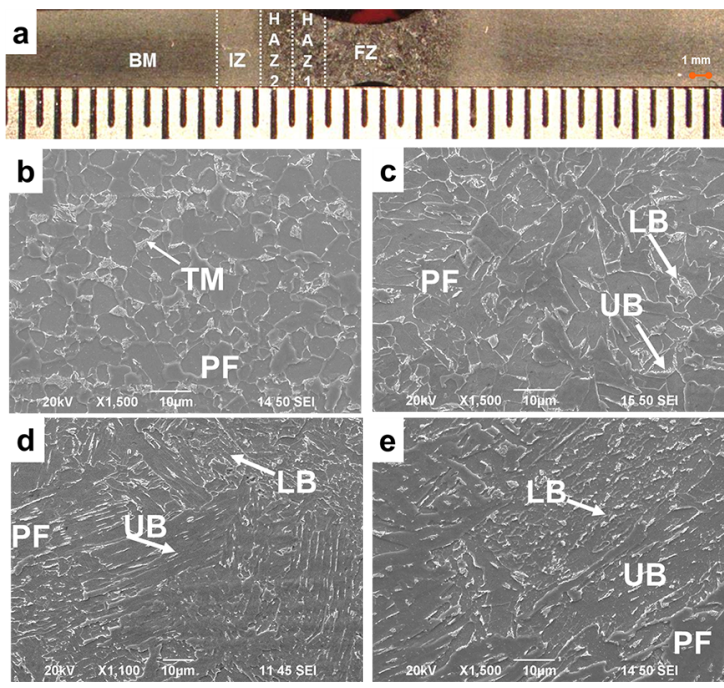

Figure 2. SEM micrographs showing resultant phases of the AHSS DP600 in various weld regions. (a) Overall view, (b) IZ, (c) HAZ 2, (d) HAZ 1 and (e) FZ.

during tempering of martensite. The microstructural change during tempering is generally understood to be composed of three main stages. The first stage consists of the formation of transition carbide, and thus a reduction in carbon content in the matrix over the tempering range of 373-523 K. The second stage corresponds to the transformation of retained austenite to ferrite and cementite over a temperature range of 473-573 K. In the third stage, the replacement of the transition carbide and low-carbon martensite by cementite and ferrite occurs between 523 and $623 \mathrm{~K}$. It has been shown that the strength of the tempered martensite is related to its microstructure, including effects being carbon segregation to dislocations, formation of $\varepsilon$-carbide, precipitation of cementite, recovery of dislocation structures and recrystallization of ferrite $^{17-21}$. During welding of DP600 steel by GTAW process the temperature was enough to transform phases in the IZ to tempered martensite (TM) and ferrite, among the published works, Easterling et al. ${ }^{22}$ investigated the modelling the weld thermal cycle and transformation phases in arc welding, demonstrated that the temperature reached in the zone between base metal and heat affected zone named IZ was of approximately $623 \mathrm{~K}^{22}$.

Table 1. Chemical composition (wt $\%$ ) of the AHSS DP 600.

\begin{tabular}{cccccccccccc}
\hline Steel & $\mathrm{C}$ & $\mathrm{Mn}$ & $\mathrm{P}$ & $\mathrm{Si}$ & $\mathrm{Cr}$ & $\mathrm{Ni}$ & $\mathrm{Mo}$ & $\mathrm{Cu}$ & $\mathrm{V}$ & $\mathrm{Nb}$ & $\mathrm{Ti}$ \\
\hline DP600 & 0.08 & 1.51 & 0.012 & 0.1 & 0.02 & $<0.04$ & 0.01 & 0.025 & $<0.004$ & 0.007 & 0.007 \\
\hline
\end{tabular}


In the heat affected zones and the fusion zone of the welded DP600 steel, the same phases were found, from these micrographs it is evident that the exhibited microstructure in the steel were UB and LB with some areas of PF, The presence of bainites in the HAZ agrees with the SEM observations of López et al. ${ }^{23}$.

\subsection{Phase quantification}

Quantitative determinations of the various phases in the BM, IZ and heat affected zones are given in Figure 3, the ten images of scanning area for AFM was used with scan heads of nominally $50 \times 50 \mu \mathrm{m}^{2}$ scanning IZ and BM zones; and the phases quantifications obtained by the ten SEM images were carry out with an area of $85 \times 62 \mu \mathrm{m}^{2}$. Notice from this figure that there is not a significant variation in the exhibited amounts of PF in the IZ when compared with the BM. In the case of TM the vol. \% present in the IZ was determined by image analysis of OM compared with the ones found by SEM and AFM (Figure 4 a). From the OM and SEM showed that the average of TM was of $11.91 \%$. From Figure 4 (a) images obtained as the results of software WSxM solution ${ }^{24}$ and using tapping mode to obtain topography and phase contrast scans of AFM, considered the height and roughness for phase's quantification. The statistical analysis of the surface roughness and height of samples help to identify every phase in the IZ. The substructure of the martensite differs clearly from that of the polygonal ferrite, whose roughness is lower and allows its identification (37 nm for martensite compared with 15 $\mathrm{nm}$ for polygonal ferrite). Ferrite found it in the lower areas $0.150 \mu \mathrm{m}$ of height and, finally, martensite in the highest level $(0.335 \mu \mathrm{m})$.It is evident that the vol. \% TM downs up to $5.25 \%$. In the case of UB and LB is necessary to considerate the height and roughness in intermediate values between PF and TM. The great advantage of the AFM compared with the scanning electron microscope (SEM) is the possibility of imaging surfaces in different environments, without any vacuum or special sample treatment, with very high resolution. It also has the ability to evaluate quantitatively selected surface features, including statistical analysis of the surface roughness, which is not possible with OM or SEM images $^{25-26}$. In particular, the amounts of ferrite decrease in the HAZ $1(11 \%)$ and in the HAZ $2(71.54 \%)$ compared with $84 \%$ in the BM by OM images analysis. In contrast, there is a slight increase in the amount of UB and LB in HAZ 2. Finally in the HAZ 1 the percentage of UB increase up to $85 \%$ and $14 \%$ of LB in the phase's quantification by SEM images analysis. The microstructure of bainite depends mainly on the temperature at which it forms, at high temperatures (623-823 K) bainite consist of needles or laths of ferrite with cementite precipitates between the laths, this is known as upper bainite. At sufficiently low temperature the morphology of bainite changes from laths into plates and the carbide dispersion becomes much finer, rather like in tempered martensite (lower bainite) ${ }^{12}$. Figures 4 (b)-(e) show a microstructure of the FZ obtained by AFM, in this case the phase's quantification was not considered to report in this work because was not applicable besides HAZ 1 and 2 .

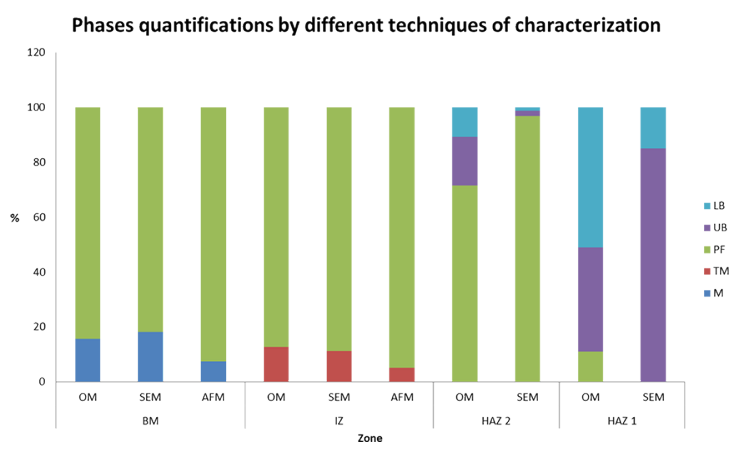

Figure 3. Image analysis results of OM compared with the ones found by SEM and AFM in various welded regions.

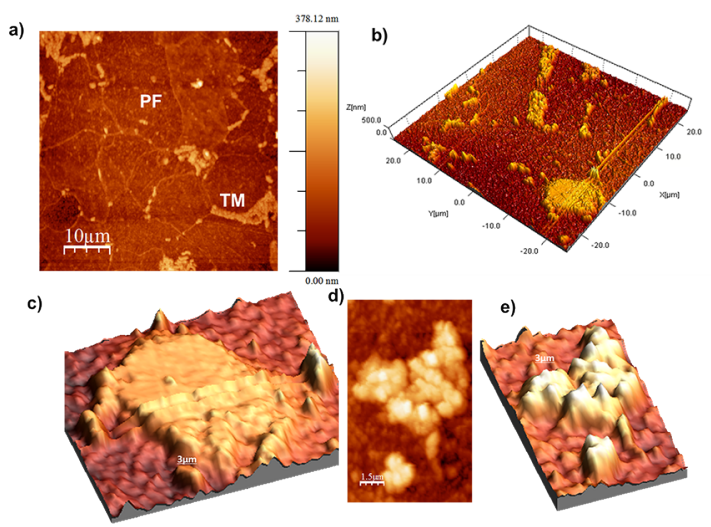

Figure 4. AFM image of a) IZ, b) 3D image of micrograph c) bainite 3D image, d) and e) martensite images.

\subsection{Microhardness}

Microhardness profiles for the various regions of the welded DP600 steel using GTAW process is shown on Figure 5. The welded regions confirm that relatively high amounts of upper and lower bainite developed in the HAZ 1 and FZ. Notice the relatively elevated hardness (near 210 HV0.5), indicating a significant development of diffusionless phases in these regions. The IZ exhibited significant decrees in hardness near to $155 \mathrm{HV} 0.5$ compare to $215 \mathrm{HV} 0.5$ in BM. In particular the microhardness profiles in IZ are attributed to the development of $11.91 \%$ of tempered martensite with a mixture of $88 \%$ of PF. IZ softening exists during welding of tempered steels it is inevitable. The degree of softening in the IZ is a function of the weld thermal cycle (which is a characteristic of the welding process), the kinetics of the phase transformations, and the chemistry of the steel $^{27}$.

\section{Conclusion}

Phase quantification of a thin $(2.5 \mathrm{~mm})$ sheet of DP600 steel welded GTAW process has been investigated using OM, as well as SEM and AFM using images pro plus analyzer. 


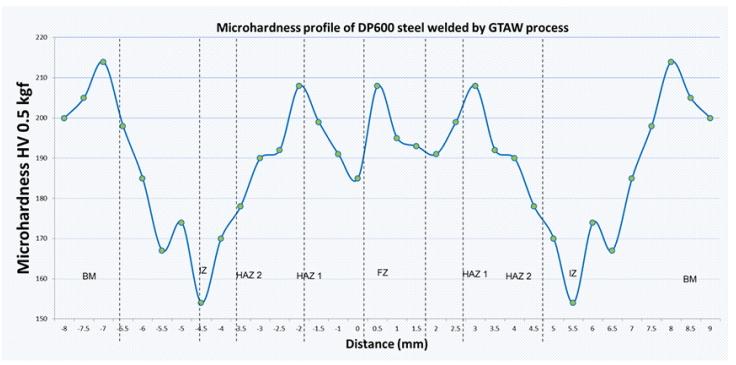

Figure 5. Exhibited microhardness profiles in the various regions of the welded DP600 steel using GTAW process.

AFM images enabled the identification of $\mathrm{M}$, TM and PF in the base metal and intercritical zone. In turn, quantitative determinations of the relative amounts of these phases were possible. The AFM offers substantial benefits in comparison with the others microcopy techniques, namely quantitative data acquisition in three dimensions, minimal sample preparation times, and effective magnifications, also its ability to evaluate quantitatively select surface features. The topographic study of the DP600 steel samples showed that the higher areas in the samples correspond to the martensitic phases and the lower areas correspond to ferrite. SEM images were also used to confirm the amounts of martensite in the BM compare with the tempered martensite development in the IZ. The microhardness profiles confirm IZ softening exists during welding of tempered DP600 steel with hardness near to 155 HV0.5 compare to 215 HV0.5 in BM. AFM was used with scan heads of nominally $50 \times 50 \mu \mathrm{m}^{2}$ scanning IZ and BM areas; and the phases quantifications obtained by SEM images were carry out with an area of $85 \times 62 \mu \mathrm{m}^{2}$. In the case of TM the vol. \% present in the IZ obtained by OM and SEM showed that the average of TM was of $11.91 \%$ compare with $5.25 \%$ obtained by AFM. This result is attributed to the selected examination locations. Nevertheless, when selecting the same scanning areas, the obtained results will be without variation.

\section{References}

1. Biro E, McDermid JR, Embury JD, Zhou Y. Softening Kinetics in the Subcritical Heat-Affected Zone of Dual-Phase Steels. Metallurgical and Materials Transactions A. 2010;41(9):2348-2356.

2. Tiziani A, Ferro P, Cervo R, Durante M. Effects of different welding technologies on metallurgical and mechanical properties of DP600 steel welded joints. La Metallurgia Italiana. 2011;1:27-34.

3. Mohandas T, Reddy GM, Kumar BS. Heat-affected zone softening in high strength low alloy steels. Journal of Materials Processing Technology. 1999;88(1-3):284-294.

4. Samek L, De Moor E, Penning J, Speer JG, De Cooman BC. Static strain aging of microstructural constituents in transformation induced plasticity steel. Metallurgical and Materials Transactions A. 2008;39(11):2542-2554.
5. Speer A, Matlock D. Color tint-etching for multiphase steels. Advanced Materials \& Processes. 2003;161(2):27-30.

6. Zhang MY, Zhu FX, Zheng DS. Mechanical Properties and Retained Austenite Transformation Mechanism of TRIP-Aided Polygonal Ferrite Matrix Seamless Steel Tube. Journal of Iron and Steel Research, International. 2011;18(8):73-78.

7. De Wit FM, Poulis JA. Joining technologies for automotive components. In: Rowe J, ed. Advanced Materials in Automotive Engineering. Cambridge: Woodhead Publishing; 2012. p. 315-329.

8. Xiong J, Li S, Gao F, Zhang J. Microstructure and mechanical properties of Ti6321 alloy welded joint by GTAW. Materials Science and Engineering: A. 2015;640:419-423.

9. Tumuluru MD. Resistance spot welding of coated high-strength dual-phase steels. Welding Journal. 2006;85(8):31-37.

10. Oliver S, Jones TB, Fourlaris G. Dual phase versus TRIP strip steels: Microstructural changes as a consequence of quasi-static and dynamic tensile testing. Materials Characterization. 2007;58(4):390-400.

11. Dinda S, Diaz R. The partnership for a new generation of vehicles (PNGV) and its impact on body engineering. In: Proceedings of the International Body Engineering Conference; 1995 Oct 31-Nov 2; Detroit, MI, USA: Advanced Technologies and Processes; 1995. p. 5-8

12. Porter DA, Easterling KE. Phase transformation in metals and alloys. $2^{\text {nd }}$ ed. Taylor and Francis: Boca Raton; 2004.

13. De Meyer M, Vanderschueren D, De Cooman B. The Influence of Al on the Properties of Cold Rolled C-Mn-Si TRIP Steels. Iron and Steelmaker. 2000;27(2):55-63.

14. Johnson D, Hilal N. Characterisation and quantification of membrane surface properties using atomic force microscopy: A comprehensive review. Desalination. 2015;356:149-164.

15. Fujisawa S, Kizuka T. Lateral displacement of an AFM tip observed by in-situ TEM/AFM combined microscopy: The effect of the friction in AFM. Tribology Letters. 2003;15(2):163-168.

16. Hoefnagels JPM, Tasan CC, Peters FJ, Geers MGD. Micromechanical Characterization of Ductile Damage in DP Steel. In: Ventura $\mathrm{CE}$, Crone WC, Furlong C, eds. Experimental and Applied Mechanics, vol. 4. New York: Springer; 2013. p. 29-35.

17. Ohmura T, Hara T, Tsuzaki K. Evaluation of temper softening behavior of $\mathrm{Fe}-\mathrm{C}$ binary martensitic steels by nanoindentation. Scripta Materialia. 2003;49(12):1157-1162.

18. Krauss G. Steels: Heat Treatment and Processing Principles. $2^{\text {nd }}$ ed. Materials Park; ASM International; 1989. p. 218.

19. Speich GR. Tempering of low-carbon martensite. Transactions TMS-AIME. 1969;245:2553-2564.

20. Speich GR, Leslie WC. The effect of the carbon concentration on the relative fraction of lath martensite, the $\mathrm{M}_{\mathrm{s}}$ temperature, and the volume fraction of retained austenite. Materials Transactions. 1972;3:1043-1048.

21. Caron RN, Krauss G. The tempering of Fe-C lath martensite. Metallurgical Transactions. 1972;3(9):2381-2389.

22. Easterling KE. Modelling of the weld thermal cycle and transformation behavior in the HAZ. London: The Institute 
of Materials, Mathematical Modelling of Weld Phenomena; 1993. p. 183-200.

23. López Cortéz VH, Pérez Medina GY, Reyes Valdéz FA, López HF. Effects of the heat input in the mechanical integrity of the welding joints welded by GMAW and LBW process in Transformation Induced Plasticity steel (TRIP) used in the automotive industry. Soldagem \& Inspeção. 2010;15(3):234-241.

24. Horcas I, Fernández R, Gómez-Rodríguez JM, Colchero J, Gómez-Herrero J, Baro AM. WSXM: a software for scanning probe microscopy and a tool for nanotechnology. Review Scientific Instruments. 2007;78(1):013705.
25. Garcia-Garcia AL, Dominguez-Lopez I, Lopez-Jimenez L, Barceinas-Sanchez O. Comparative quantification and statistical analysis of $\eta^{\prime}$ and $\eta$ precipitates in aluminum alloy AA7075-T651 by TEM and AFM. Materials Characterization. 2014;87:116-124.

26. Ros-Yáñez T, Houbeart Y, Mertens A. Characterization of TRIPassisted multiphase steel surface topography by atomic force microscopy. Materials Characterization. 2001;47(2):93-104.

27. Min D, Xin-hua T, Feng-gui L, Shun Y. Welding of quenched and tempered steels with high-spin arc narrow gap MAG system. The International Journal of Advanced Manufacturing Technology. 2011;55(5):527-533. 